Agus Nugroho Setiawan ${ }^{1}$ Sukuriyati

Susilo Dewi

${ }^{1}$ Prodi A groteknologi, U niversitas

M uhammadiyah Yogyakarta

2Prodi A groteknologi, U niversitas

M uhammadiyah Yogyakarta

Jalan B rawijaya, Tamantirto, K asihan,

B antul, Yogyakarta 55163

1E mail: agus_enes@yahoo.com

\section{Pemberdayaan Kelompok Aisyiyah dalam Pengelolaan Salak Pondoh di Kecamatan Turi, Sleman}

https:/ / doi.org/ 10.18196/ bdr.427

\title{
PENDAHULUAN
}

Turi yang merupakan salah satu kecamatan di Kabupaten Sleman, dengan tanaman utamanya adalah salak pondoh. Pada umumnya buah salak pondoh dikonsumsi dalam bentuk segar dan tidak dapat disimpan dalam jangka waktu yang lama karena mudah kering dan tidak segar lagi. Sebagaimana umumnya buah dan sayuran, salak masih melangsungkan proses metabolisme setelah dipanen. Reaksi metabolisme akan mengakibatkan perubahan mutu, penampakan dan kondisi buah. Perubahan tersebut disebabkan terjadinya penguapan air, konversi enzimatis menjadi gula, pembentukan atau pelepasan flavor, konversi enzimatis senyawa paktin, sintesa atau degradasi pigmen, kerusakan vitamin dan lainnya (Pantastico, 1989). Proses respirasi dan transpirasi sangat 
berkaitan dengan mutu simpan buah selama penanganan dan penyimpanan dimana akan menyebabkan susut pasca panen seperti susut bobot, susut kualitaskarena perubahan wujud (kenampakan), cita rasa, warna atau tekstur yang menyebabkan salak pondoh kurang disukai konsumen, susut gizi yang berpengaruh terhadap kualitas buah. Dalam keadaan seperti ini, harga jual buah salak pondoh menjadi sangat rendah (Anonim, 2012; Anonim, 2013a).

Di wilayah Kecamatan Turi terdapat banyak organisasi sosial kemasyarakatan, dan salah satunya adalah A isyiyah yang merupakan kelompok jamaah ibu-ibu, baik yang berada di tingkat kecamatan yang tergabung dalam Pimpinan C abang A isyiyah (PCA) maupun tingkat desa/ dusun dalam Pimpinan Ranting Aisyiyah (PRA). Sebagian besar anggota Aisyiyah mempunyai lahan salak pondoh dan merupakan petani salak pondoh. Pada umumnya, anggota Aisyiyah menjual hasil panen salak pondoh ke tengkulak atau ke pengepul di wilayah tersebut. Permasalahan yang sering dihadapi adalah harga salak pondoh yang sangat fluktuatif. Pada saat musim panen raya hasil salak pondoh melimpah di pasaran sehingga harga salak dapat turun drastis sehingga dibeli tengkulak hanya dengan harga Rp. 1.500-Rp. 2.000 per kg. Padahal pada saat tidak panen raya, salak pondoh dapat dijual dengan harga antara Rp. 4.000-Rp. 5.000 per kg. Selain itu, petani tidak mempunyai kekuatan untuk menentukan harga buah salak pondoh dan tergantung pada harga dari tengkulak. $\mathrm{H}$ al ini menyebabkan pada saat panen raya hasil penjualan salah pondoh dan pendapatan anggota A isyiyah sangat rendah. Permasalahan lainnya adalah pengetahuan dan ketrampilan anggota dalam mengelola hasil dan mengolah buah salak pondoh masih sangat terbatas.

Beberapa permasalahan yang dihadapi oleh kedua kelompok A isyiyah, membutuhkan penangan an yang tepat agar tidak menimbulkan dampak yangkurang baik. M endasarkan pada permasalahan yang ada pada mitra, maka prioritas permasalahan yang perlu diselesaikan dan solusi yang dilakukan adalah peningkatan nilai tambah buah salak pondoh dan peningkatan ketrampilan dalam pengelolaan paska panen salak pondoh.

Mendasarkan pada solusi untuk menyelesaikan permasalahan yang ada, maka program kegiatan pada masyarakat ini dilakukan dengan tujuan untuk meningkatkan nilai tambah buah salak pondoh melalui industri hilir pengolahan salak pondoh menjadi berbagai macam produk dan meningkatkan pengetahuan, wawasan, dan ketrampilan anggota $A$ isyiyah dalam pengelolaan paska panen dan pengolahan salak pondoh (A nonim, 2013b; Anonim, 2013c). Dengan demikian, anggota Aisyiyah akan mempunyai pengetahuan, wawasan dan ketrampilan dalam mengelola salak pondoh dengan baik 
sehingga buah salak mempunyai nilai tambah yang tinggi dan dapat meningkatkan pendapatan keluarga (Anonim, 2013d).

\section{METODE PELAKSANAAN}

U ntuk mencapai tujuan dan luaran sesuai permasalahan yang dihadapi, digunakan beberapa metode, yang meliputi : 1) penyuluhan, 2) fasilitasi peralatan dan transfer teknologi, 3) pelatihan dan praktek aplikasi teknologi, serta 4) pendampingan dan monitoring evaluasi

Kegiatan penyuluhan dilakukan dengan mengumpulkan anggota Aisyiyah untuk mengikuti penyuluhan pengelolaan paska panen dan pengolahan buah salak pondoh. Beberapa materi yang diberikan antara lain arti penting penanganan paska panen salak pondoh, cara meningkatkan nilai tambah buah salak pondoh dan peluang ekonomi produk olahan salak pondoh.

Fasilitasi pelatihan dan praktek pembuatan produk olahan buah salak pondoh, dilakukan transfer teknologi dengan pengadaan mesin pembuat keripik salak berupa vacum frying, alat penumbuk biji salak, serta fasilitas lain yang mendukung kegiatan ini. Demonstrasi dan pelatihan dilakukan dengan simulasi praktek pembuatan produk olahan buah salak pondoh menggunakan peralatan dan bahan yang sudah disiapkan oleh Tim Pelaksana program. Pelatihan awal penggunaan alat dilakukan oleh vendor peralatan, dengan diikuti oleh Tim Pelaksana program dan Pengurus Aisyiyah. Demonstrasi dan pelatihan, anggota Aisyiyah melakukan praktek pembuatan produk olahan buah salak pondoh sampai pengemasannya dengan dibimbing oleh Tim Pelaksana program. Kegiatan pendampingan dilakukan secara periodik untuk membina dan mendampingi mitra sampai berhasil melakukan praktek pembuatan produk olahan buah salak pondoh.

Peserta (khalayak sasaran) program pengabdian pada masyarakat yaitu pimpinan dan anggota Pimpinan Cabang Aisyiyah (PCA) Turi dan Pimpinan Ranting Aisyiyah (PRA) Kembangarum, yang dipilih oleh Pimpinan Aisyiyah.

\section{HASIL DAN PEMBAHASAN}

Persiapan dan Koordinasi. U ntuk menjamin berjalannya program pengabdian pada masyarakat, langkah awal yang dilakukan adalah koordinasi, untuk menyamakan persepsi antar pihak yang terkait serta menyusun langkah strategis pelaksanaan program. Koordinasi dilakukan secarainternal dan eksternal. Koordinasi internal dilakukan antara Tim Pelaksana dengan Tim Pendukung Pelaksana yaitu laboran dan mahasiswa, untuk 
membahas tata kegiatan dan waktu pelaksana, serta tanggung jawab setiap anggota Tim Pelaksana. Kegiatan ini juga digunakan untuk mengevaluasi kegiatan yang sudah dilakukan dan menyusun rencana kegiatan berikutnya.

Koordinasi eksternal dilakukan antara Tim Pelaksana dengan mitra yaitu PCA Turi dan PRA Kembangarum. Pada kegiatan ini disampaikan tentang gambaran umum kegiatan dan didiskusikan pengaturan jadual kegiatan dengan Pimpinan Aisyiyah.

H asil evaluasi program pengabdian pada masyarakat menunjukkan bahwa peserta yang berpartisipasi cukup banyak, meliputi pimpinan dan anggota Aisyiyah, terutama ibu-ibu rumah tangga dan sebagian kecil peserta adalah remaja ( $G$ ambar 1 ), baik di Cabang Aisyiyah Turi maupun Ranting A isyiyah Kembangarum. Jumlah peserta yang banyak tersebut disebabkan oleh potensi salak pondoh dan kemanfaatan produk olahan yang tinggi.
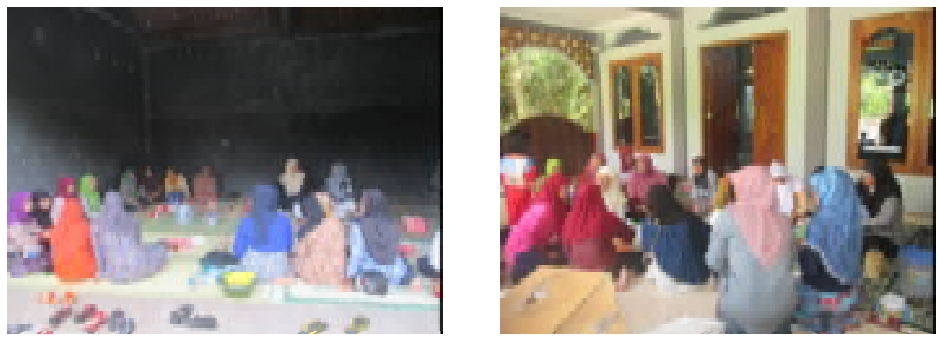

Gambar 1. Peserta pelatihan pengolahan salak pondoh di Aisyiyah

Persiapan alat dan bahan. Untuk mendukung kegiatan praktek pengolahan salak pondoh bagi mitra, dilakukan penyiapan peralatan dan bahan sesuai yang dibutuhkan, oleh Tim Pelaksana dengan terlebih dahulu dikonsultasikan dengan mitra. Alat-alat yang dipersiapkan berupa alat memasak antara lain kompor, mixer, cup sealer, timbangan, dan sebagainya (G ambar 2).
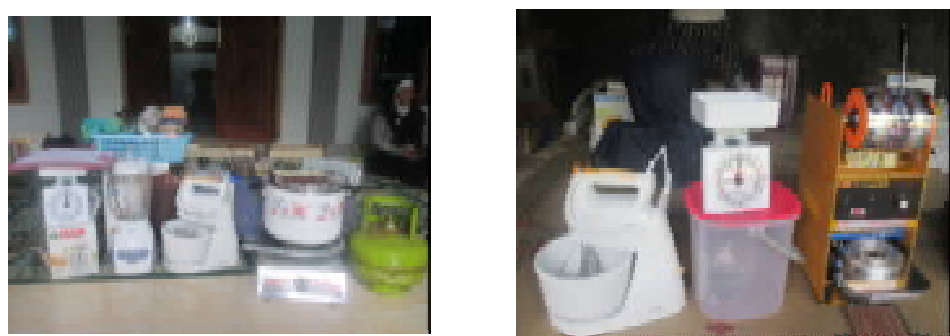

Gambar 2. Penyiapan alat pengolahan salak pondoh

Penyuluhan. Kegiatan sosialisasi program pengabdian pada masyarakat diikuti oleh Pimpinan dan anggota Aisyiyah sebagai penerima program, sekaligus dilakukan penyuluhan dan diskusi tentang pengelolaan hasil dan pengolahan salak pondoh. $\mathrm{Nara}$ sumber dalam kegiatan ini adalah Tim Pelaksana yang sudah mempunyai pengetahuan 
dan wawasan dalam pengelolaan salak pondoh, dan menghadirkan nara sumber praktisi dari Laboratorium A gribisnis U M Y yang sudah mempunyai banyak pengalaman dalam pengolahan hasil pertanian ( $\mathrm{Gambar}$ 3). M ateri yang disampaikan dalam penyuluhan adalah potensi salak pondoh dalam mendukung ekonomi rumah tangga dan penanganan salak pondoh dengan pengolahan menjadi berbagai macam produk. D alam penyuluhan banyak tanggapan dari peserta, terutama pertanyaan tentang jenis dan umur salak yang dapat diolah, ketahanan produk yang dihasilkan, dan sebagainya.
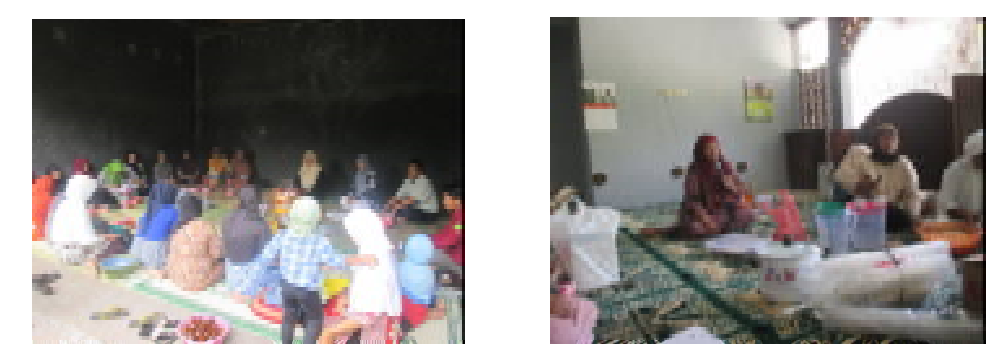

Gambar 3. Sosialisasi dan penyuluhan pengelolaan salak pondoh di PCA dan PRA

Praktek Pengolahan salak Pondoh. Setelah kegiatan penyuluhan selesai dilanjutkan praktek pengolahan salak pondoh, dengan kegiatan awal yang dilakukan adalah penyiapan bahan dan alat oleh Tim Pelaksana. Kegiatan praktek pengolahan salak dilakukan dengan tujuan untuk memberikan ketrampilan dan pengalaman kepada peserta. Kegiatan pengolahan salak pondoh dimulai dengan pengupasan salak pondoh dari kulitnya dan dilanjutkan dengan pengirisan salak pondoh menjadi kecil-kecil (Gambar 4).
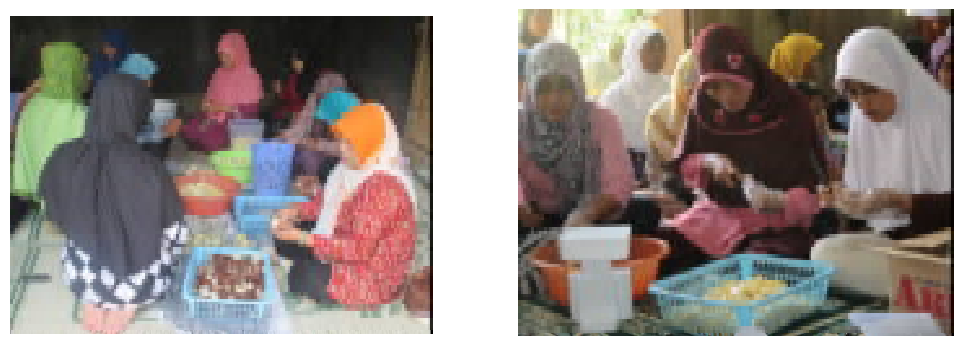

Gambar 4. Pengupasan dan pengirisan salak pondoh

Bentuk dan ukuran irisan salak pondoh disesuaikan dengan tujuan akhir produk yang akan dibuat. U ntuk pembuatan manisan atau asinan, ukuran irisan buah salak pondoh dibuat relatif kecil dengan bentuk yang teratur dan menarik, sedangkan untuk kepentingan pembuatan sari buah dan brownies, irisan dapat dilakukan tidak dengan teratur karena buah salak akan dihaluskan dengan blender (Gambar 5). Selanjutnya semua bahan dicampur dengan bumbu-bumbu yang diperlukan untuk diolah. Pengolahan manisan dan asinan buah salak pondoh, dilakukan dengan cara mencampur buah salak pondoh yang sudah diiris dengan air dan gula sesuai kebutuhan. 

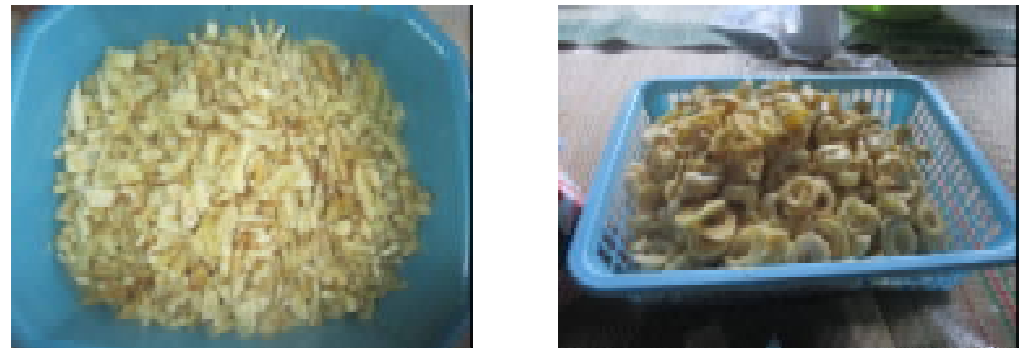

G ambar 5. Salak pondoh yang sudah diiris siap untuk diolah

Perbedaan pembuatan manisan dan asinan buah salak pondoh terletak pada bahan yang digunakan. Pada manisan bahan yang digunakan hanyalah air dan gula, sedangkan pada asinan juga ditambah dengan garam. Penggunaan gula dan garam adalah untuk pengawetan buah salak pondoh olahan. Pada pembuatan sari buah, buah salak pondoh yang sudah dipotong dicampur dengan air dan diblender sampai dihasilkan ekstraksi yang halus, kemudian dipanaskan dengan tujuan sterilisasi (G ambar 6).
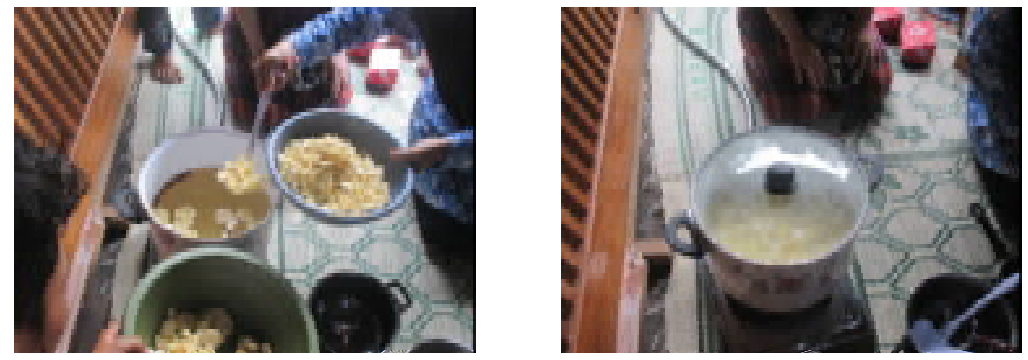

Gambar 6. Pemanasan buah salak pondoh untuk manisan dan asinan

Setelah mendidih, sari buah dan asinan salak pondoh dimasukkan dalam kemasan gelas plastik dalam keadaan panas dan tutup menggunakan cup sealer (Gambar 7) agar terjamin lebih awet untuk disimpan.
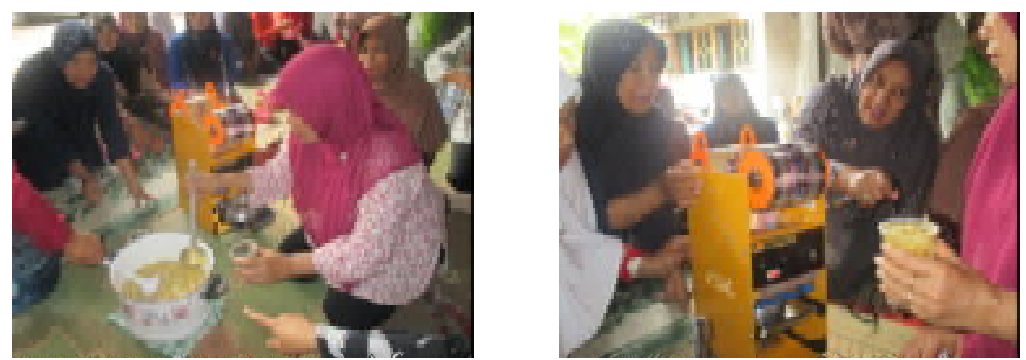

Gambar 7. Pengemasan manisan dan asinan buah salak pondoh

U ntuk mempercepat pendinginan dan mengevaluasi penutupan menggunakan cup sealer, gelas plastik yang sudah berisi sari buah, manisan atau asinan, dimasukkan dalam 
air dingin. Jika sudah dingin, hasil olahan dapat disajikan untuk diminum atau dimasukkan dalam lemari pendingin (Gambar 8). Dengan tempat penyimpanan pendingin yang baik, minuman olahan buah salak pondoh dapat bertahan sampai 6 bulan. M eskipun minuman olahan buah salak pondoh sudah dipanaskan dan berada dalam kemasan, namun dapat mengalami kerusakan akibat mikrobia yang mungkin terbawa udara yang mengisi kemasan.
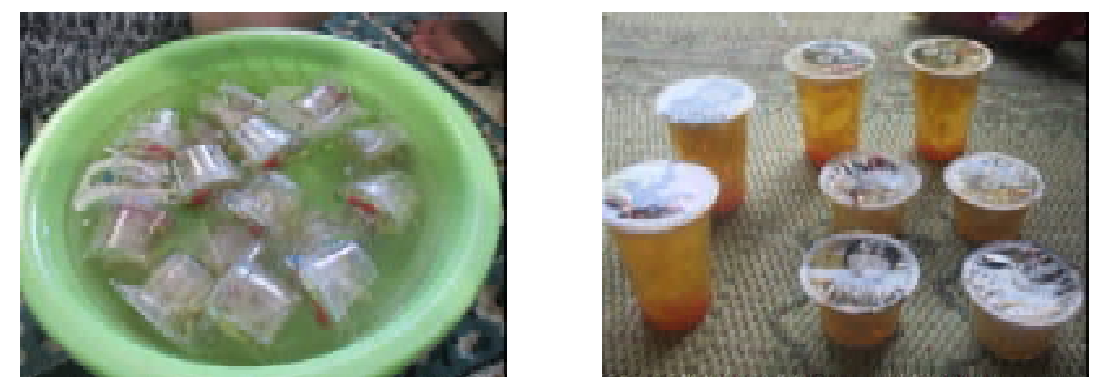

Gambar 8. Produk minuman olahan buah salak pondoh

Pengolahan buah salak pondoh menjadi brownies dilakukan dengan menghaluskan buah salak pondoh menggunakan blender. Selanjutnya dicampur dengan gula dan bubuk coklat sesuai kebutuhan, dan diaduk sampai merata menggunakan mixer. Setelah bercampur secara merata, selanjutnya adonan dituangkan ke dalam panci pencetak (Gambar 9).
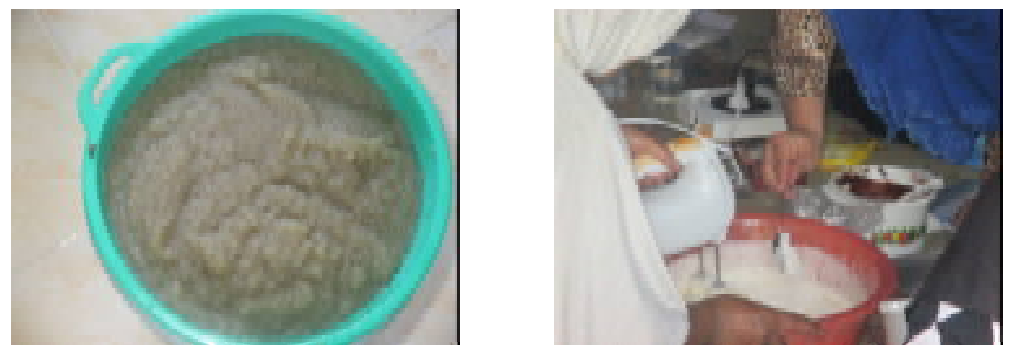

Gambar 9. Pembuatan adonan brownies salak pondoh

A donan brownies yang sudah dimasukkan dalam panci pencetak, selanjutnya dikukus menggunakan panci pengukus selama kurang lebih 30 menit, sampai brownies matang, yang ditunjukkan dengan tekstur yang sudah memadat dan warna berubah menjadi lebih coklat (Gambar 10). 

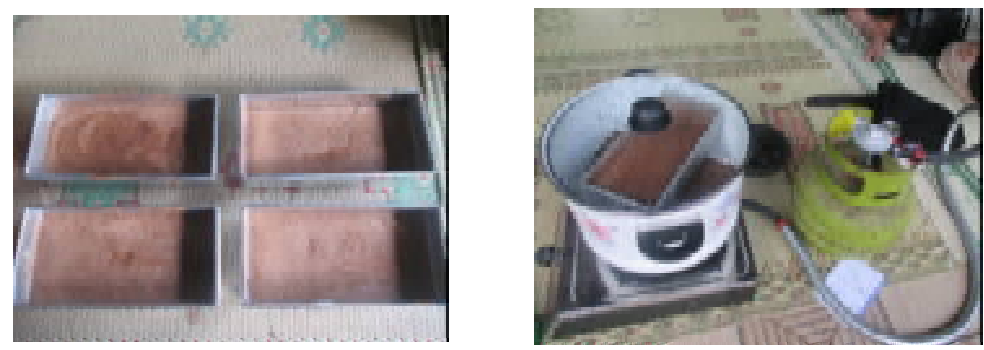

Gambar 10. Proses pembuatan brownies salak pondoh

B rownies yang sudah matang selanjutnya diturunkan dari panci pengukus, dan dibiarkan sampai cukup dingin. Selanjutnya, untuk menambah rasa dapat ditaburkan serutan keju di atas brownies (Gambar 11). Produk olahan buah salak pondoh dalam bentuk brownies dapat bertahan dalam suhu kamar selama 3-4 hari, namun jika dimasukkan dalam lemari pendingin dapat bertahan sampai 10-14 hari. $\mathrm{H}$ al ini disebabkan suhu rendah dalam lemari pendingin dapat menghambat pertumbuhan mikrobia yang dapat menyebabkan pembusukan brownies.
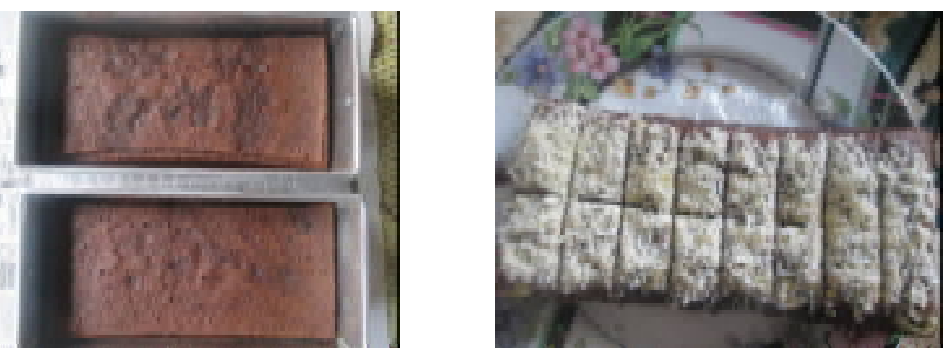

Gambar 11. Hasil olahan salak pondoh berupa brownies

Semua produk olahan buah salak pondoh menggunakan bahan-bahan alami dan tidak menggunakan bahan pengawet buatan sehingga aman untuk dikonsumsi (Gambar 12).
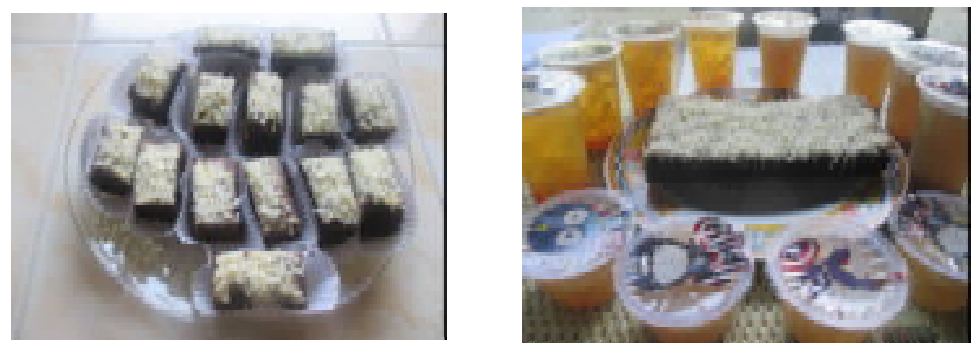

Gambar 12. Produk hasil olahan salak pondoh

Meskipun kegiatan pemberdayaan sudah berjalan dengan baik dan mampu memberikan wawasan serta ketrampilan bagi pimpinan dan anggota Aisyiyah di Kecamatan Turi, namun perlu diantisipasi munculnya masalah terutama ketersediaan 
bahan bahan baku, yaitu buah salak pondoh. Pada musim kemarau yang cukup panjang, ketersediaan air tanah mengalami penurunan dapat menyebabkan tanaman salak mengalami kekeringan, bahkan mengalami kematian sehingga produksi buah salak pondoh menurun. Sebagai akibatnya, ketersediaan buah salak pondoh menjadi terbatas, dan jika ada harganya menjadi sangat mahal. $\mathrm{H}$ al ini tentu akan berpengaruh terhadap keberlanjutan usaha produksi olahan salak pondoh. Sebaliknya pada musim hujan, ketersediaan buah salak pondoh akan kembali meningkat sehingga produksi olahan salak pondoh dapat berjalan.

Untuk menjamin keberlanjutan kegiatan pemberdayaan masyarakat, peralatan penunjang yang sudah digunakan untuk praktek pengolahan salak pondoh, diserahkan oleh Tim Pelaksana kepada mitra yaitu Pimpinan C abang Aisyiyah Turi dan Pimpinan Ranting Aisyiyah Kembangarum (G ambar 13). Bantuan peralatan pengolah buah salak pondoh tersebut, diharapkan dapat lebih memberdayakan masyarakat, terutama warga A isyiyah dalam memberikan nilai tambah buah salak pon doh di Kecamatan Turi, Sleman, DIY.
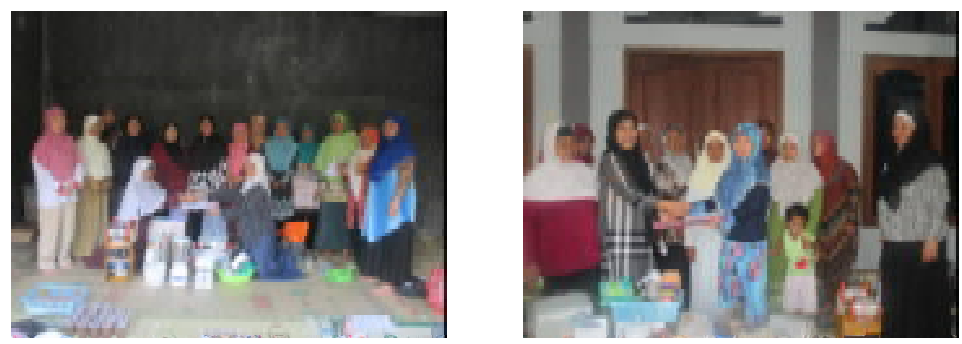

Gambar 13. Serah terima peralatan dari Tim Pelaksana kepada mitra

\section{SIM PULAN}

1. M asyarakat sasaran yaitu Pimpinan dan Anggota PCA Turi dan PRA Kemban garum, memberikan tanggapan yang san gat baik dengan berpartisipasi mengikuti kegiatan dengan sebaik-baiknya.

2. Pelaksanaan kegiatan pengabdian masyarakat pengolahan salak pondoh di PCA Turi dan PRA Kembangarum telah berjalan dengan baik, dengan beberapa kegiatan yang dilakukan adalah sosialisasi, penyuluhan dan diskusi, praktek, serta pendampingan, dengan produk yang dihasilkan berupa olahan salak pondoh berupa minuman dan brownies.

\section{UCAPAN TERIMA KASIH}

Tim Pelaksanamemberikan apresiasi dan penghargaan setinggi-tingginya kepada D P2M 
Kemenristek Dikti yang telah memfasilitasi kegiatan pengabdian pada masyarakat, Staf dan Laboran Laboratorium Produksi Tanaman U MY, mahasiswa pembantu pelaksana dan semua pihak yangtelah berpartisipasi dan ikut membantu guna kelancaran kegiatan ini.

\section{DAFTAR PUSTAKA}

Anonim. 2012. Keripik Salak Sleman Kalah Bersaing. http://www. harianjogja. com/baca/2012/04/03/ keripik-salak-sleman-kalah-bersaing-175557. diakses 29 April 2014.

Anonim, 2013a. Keripik Salak Pondoh khas Sleman. http://log.viva.co.id/ news/read/412112-keripik-salakpondoh-khas-sleman. diakses 29 April 2014.

Anonim, 2013b. Salak Olahan Tingkatkan Pendapatan Warga. http://gudeg.net/ id/news/2013/07/7544/ Salak-Olahan-Tingkatkan-Pendapatan-Warga. html. diakses 29 April 2014

Anonim, 2013c. Produsen Bakpia Salak Jogja/ Yogyakarta-Bakpia Salak Cristal. http:// jogja.storykota.com/id/ direktori-jogja/produsenbakpia-salak-jogja-yogyakarta/bakpia-salak-cristal. diakses 29 April 2014
Anonim, 2013d. Peningkatan Nilai Tambah Salak Pondoh. http://www.umy.ac.id/ peningkatan-nilai-tambah-salakpondoh.html. akses 29 April 2014.

Nur Muayyidah. 2013. Cara Membuat Dodol Salak. http://spesialresepmakanan. blogspot.com/2013/04/cara-membuatdodol-salak.html. diakses 29 April 2014.

Pantastico, Er. B. 1989. Postharvest Physiology, Handling and Utilization of Tropical and Subtropical Fruit and Vegetables.The Avi Publishing Company Inc. Westport, Connecticut. $906 \mathrm{p}$. 